\title{
Biosynthesis and biological action of pineal allopregnanolone
}

\author{
Kazuyoshi Tsutsui * and Shogo Haraguchi \\ Laboratory of Integrative Brain Sciences, Department of Biology and Center for Medical Life Science, Waseda University, Tokyo, Japan
}

\section{Edited by:}

Giulia Puja, Università degli Studi di Modena e Reggio Emilia, Italy

\section{Reviewed by:}

Hubert Vaudry, University of Rouen, France

Robert Weissert, University of Regensburg, Germany

Sarah E. London, University of Chicago, USA

\section{*Correspondence:}

Kazuyoshi Tsutsui, Laboratory of Integrative Brain Sciences,

Department of Biology and Center for Medical Life Science, Waseda University, 2-2 Wakamatsu-cho,

Shinjuku-ku, Tokyo 162-8480, Japan e-mail: k-tsutsui@waseda.jp
The pineal gland transduces photoperiodic changes to the neuroendocrine system by rhythmic secretion of melatonin. We recently provided new evidence that the pineal gland is a major neurosteroidogenic organ and actively produces a variety of neurosteroids de novo from cholesterol in birds. Notably, allopregnanolone is a major pineal neurosteroid that is far more actively produced in the pineal gland than the brain and secreted by the pineal gland in juvenile birds. Subsequently, we have demonstrated the biological action of pineal allopregnanolone on Purkinje cells in the cerebellum during development in juvenile birds. Pinealectomy (Px) induces apoptosis of Purkinje cells, whereas allopregnanolone administration to Px chicks prevents cell death. Furthermore, Px increases the number of Purkinje cells that express active caspase-3, a crucial mediator of apoptosis, and allopregnanolone administration to Px chicks decreases the number of Purkinje cells expressing active caspase-3. It thus appears that pineal allopregnanolone prevents cell death of Purkinje cells by suppressing the activity of caspase-3 during development. This paper highlights new aspects of the biosynthesis and biological action of pineal allopregnanolone.

Keywords: neurosteroids, allopregnanolone, caspase-3, apoptosis, cell survival, pineal gland, Purkinje cell

\section{INTRODUCTION}

De novo formation of neurosteroids in the brain was originally demonstrated in mammals (Corpéchot et al., 1981, 1983; Robel and Baulieu, 1985; Lanthier and Patwardhan, 1986; Robel et al., 1987; Jo et al., 1989; Mathur et al., 1993; Mellon and Deschepper, 1993; Compagnone et al., 1995; Ukena et al., 1998, 1999; Sakamoto et al., 2001b, 2003a), and subsequently in non-mammalian vertebrates, such as birds, amphibians, and fish (Mensah-Nyagan et al., 1994, 1996a,b, 1999; Tsutsui and Yamazaki, 1995; Usui et al., 1995; Vanson et al., 1996; Tsutsui et al., 1997, 1999, 2003a, 2008; Beaujean et al., 1999; Schlinger et al., 1999; Takase et al., 1999, 2002, 2011; Freking et al., 2000; Matsunaga et al., 2001, 2002, 2004a; Sakamoto et al., 2001a; Tsutsui and Schlinger, 2001; Ukena et al., 2001; Inai et al., 2003; London et al., 2003, 2006, 2010; Soma et al., 2004; Menuet et al., 2005; Do-Rego et al., 2007; London and Schlinger, 2007; Tam and Schlinger, 2007; Bruzzone et al., 2010; Haraguchi et al., 2010, 2012a; Diotel et al., 2011; Brion et al., 2012). Therefore, de novo synthesis of neurosteroids from cholesterol is considered to be a conserved property in the brain across vertebrate species (for reviews, see Baulieu, 1997; Tsutsui et al., 1999, 2000, 2003a, 2006; Compagnone and Mellon, 2000; Mellon and Vaudry, 2001; Tsutsui and Mellon, 2006; Do-Rego et al., 2009).

Until recently, it was generally accepted that neurosteroids are produced in glial cells and neurons which are located in the brain and peripheral nervous systems (for reviews, see Baulieu, 1997; Tsutsui et al., 1999, 2000, 2003a, 2006; Compagnone and Mellon, 2000; Mellon and Vaudry, 2001; Tsutsui and Mellon, 2006; Do-Rego et al., 2009). However, we recently discovered that the pineal gland actively produces neurosteroids de novo from cholesterol in the juvenile chicken and quail (Hatori et al., 2011; Haraguchi et al., 2012b). Notably, allopregnanolone ( $3 \alpha, 5 \alpha-$ tetrahydroprogesterone; $3 \alpha, 5 \alpha-\mathrm{THP})$ is a major neurosteroid produced in the pineal gland (Haraguchi et al., 2012b). Importantly, allopregnanolone secreted by the pineal gland prevents cell death of Purkinje cells by suppressing the activity of caspase-3, a crucial mediator of apoptosis, in the cerebellum during development (Haraguchi et al., 2012b).

\section{NEUROSTEROIDOGENIC CELLS IN THE BRAIN}

Past studies demonstrated that oligodendrocytes are the primary site for neurosteroid formation in the brain (for reviews, see Baulieu, 1997; Compagnone and Mellon, 2000). Subsequently, astrocytes were shown to express steroidogenic enzymes (Mellon and Deschepper, 1993). Based on extensive studies, it was generally accepted that glial cells are the site for neurosteroid formation in the brain. However, whether neurons located in the brain produce neurosteroids was unknown in vertebrates until the middle 1990s. We discovered that Purkinje cells, a major neuronal population actively produce a variety of neurosteroids de novo from cholesterol in the brain of various vertebrates (Tsutsui and Yamazaki, 1995; Usui et al., 1995; Ukena et al., 1998, 1999; Takase et al., 1999; Matsunaga et al., 2001; Sakamoto et al., 2001a,b, 2003a; Agís-Balboa et al., 2006, 2007). The Purkinje cell expresses several kinds of key steroidogenic enzymes in rat (Furukawa et al., 1998; Ukena et al., 1998, 1999; Sakamoto et al., 2003a). In the rat hippocampus, the expression of steroidogenic enzymes has also been found in pyramidal neurons in the CA1-CA3 regions as well as granule cells in the dentate gyrus (Kimoto et al., 2001; Hojo et al., 2004; Okamoto et al., 2012). In addition to these 
brain neurons, the expression of steroidogenic enzymes has been reported in neurons in the retinal ganglion, sensory neurons in the dorsal root ganglia and motor neurons in the spinal cord of rat (Guarneri et al., 1994; Compagnone et al., 1995). Based on these findings, not only glial cells but also neurons have been demonstrated as the sites of neurosteroid formation in the central and peripheral nervous systems (for reviews, see Baulieu, 1997; Tsutsui et al., 1999, 2000, 2003a, 2006; Compagnone and Mellon, 2000; Mellon and Vaudry, 2001; Tsutsui and Mellon, 2006; Do-Rego et al., 2009).

\section{BIOSYNTHESIS OF NEUROSTEROIDS IN THE PINEAL GLAND NEUROSTEROIDS FORMED IN THE PINEAL GLAND}

The pineal gland that is an endocrine organ located close to the parietal region of the brain is known to transduce photoperiodic changes to the neuroendocrine system by rhythmic secretion of melatonin. However, the biosynthesis of neurosteroids in this endocrine organ was, until recently, unknown. We recently provided new evidence that the pineal gland is a major neurosteroidogenic organ actively producing a variety of neurosteroids de novo from cholesterol (Hatori et al., 2011; Haraguchi et al., 2012b) (Figure 1). This is a paradigm shift of neurosteroid formation, because it was accepted that neurosteroids are synthesized only in glial cells and neurons which are located in the brain and peripheral nervous systems for the past 30 years (for reviews, see Baulieu, 1997; Tsutsui et al., 1999, 2000, 2003a, 2006; Compagnone and Mellon, 2000; Mellon and Vaudry, 2001; Tsutsui and Mellon, 2006; Do-Rego et al., 2009).
Pregnenolone is a main precursor of steroid hormones and the production of pregnenolone is initiated by cleavage of the cholesterol side-chain by cytochrome P450scc (P450scc; gene name Cyp11a), a mitochondrial enzyme, in vertebrates. We first showed that the pineal gland expresses P450scc in juvenile chickens and quail by reverse transcription polymerase chain reaction (RT-PCR) analysis (Hatori et al., 2011; Haraguchi et al., 2012b) (Figure 1). P450scc antibodies stained the cells forming follicular structures in the pineal gland of juvenile birds (Haraguchi et al., 2012b). Incubation of pineal glands from juvenile birds with ${ }^{3} \mathrm{H}$-cholesterol led to the formation of radioactive pregnenolone as revealed by high-performance liquid chromatography (HPLC) analysis (Haraguchi et al., 2012b) (Figure 1). Gas chromatography-mass spectrometry (GC-MS) analysis further demonstrated the occurrence of pregnenolone in the pineal gland (Haraguchi et al., 2012b).

Subsequently, RT-PCR analyses demonstrated the expressions of key steroidogenic enzymes, such as cytochrome P450

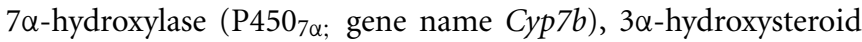
dehydrogenase $/ \Delta^{5}-\Delta^{4}$-isomerase ( $3 \alpha-H S D$; gene name $H s d 3 a$ ), $3 \beta$-hydroxysteroid dehydrogenase $/ \Delta^{5}-\Delta^{4}$-isomerase $(3 \beta$ HSD; gene name $H s d 3 b$ ), $5 \alpha$-reductase (gene name $S r d 5 a$ ), $5 \beta$-reductase (gene name $S r d 5 b$ ), cytochrome P450 $17 \alpha$ -

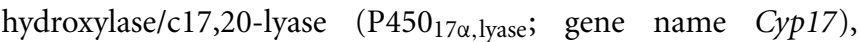
$17 \beta$-hydroxysteroid dehydrogenase (17 $\beta$-HSD; gene name $H s d 17 b)$ and cytochrome $\mathrm{P} 450$ aromatase (P450arom; gene name Cyp19) in the pineal gland of juvenile birds (Hatori et al., 2011; Haraguchi et al., 2012b) (Figure 1).

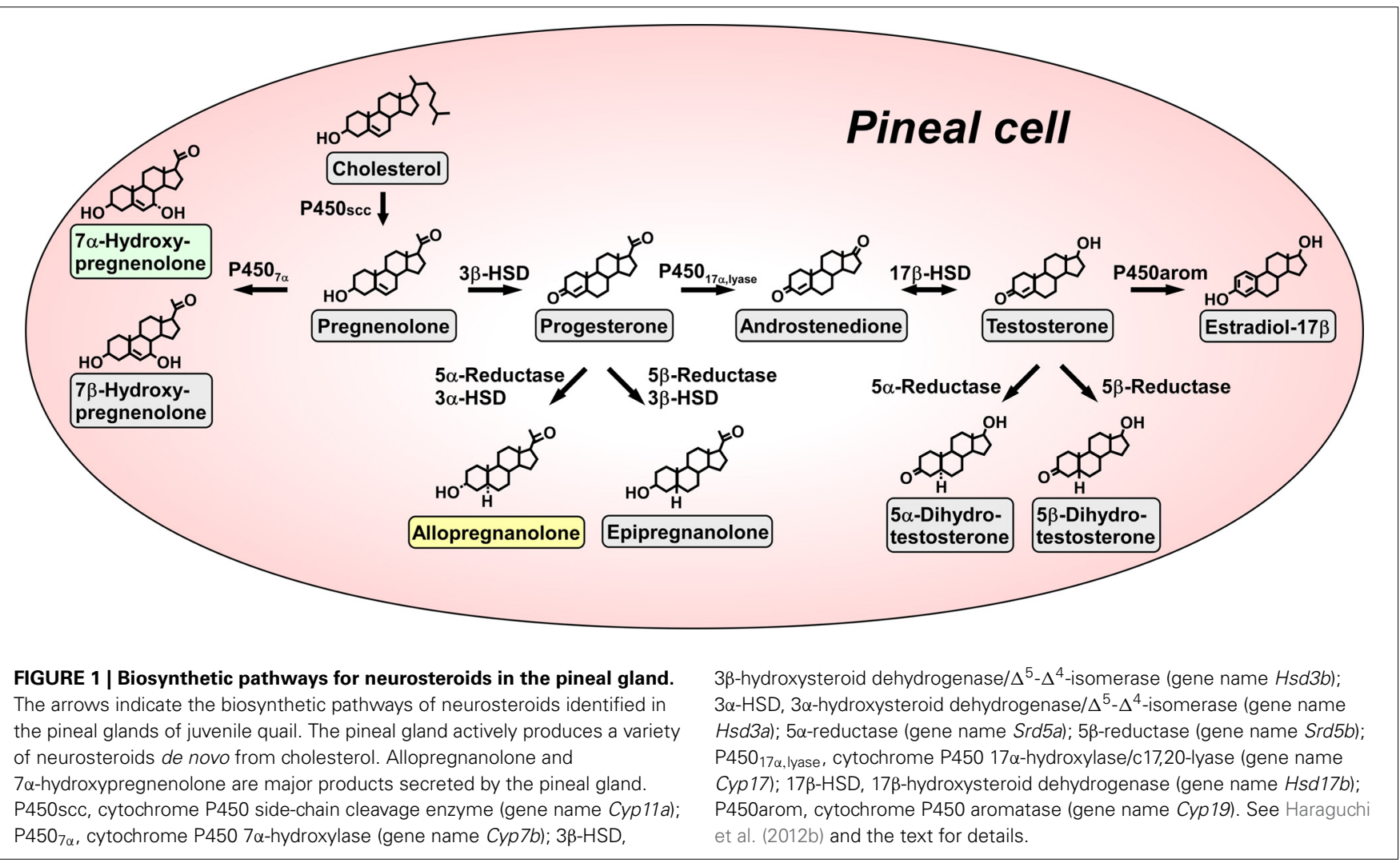


Biochemical studies combined with HPLC and GC-MS analyses were further conducted to demonstrate the biosynthetic pathways of neurosteroids in the pineal gland. Incubation of pineal glands from juvenile birds with ${ }^{3} \mathrm{H}$-pregnenolone as a precursor led to the formation of $7 \alpha$ - and/or $7 \beta$-hydroxypregnenolone as revealed by HPLC analysis (Haraguchi et al., 2012b) (Figure 1). In addition to these neurosteroids, progesterone, allopregnanolone $(3 \alpha, 5 \alpha-\mathrm{THP})$ and/or epipregnanolone ( $3 \beta, 5 \beta$-THP), androstenedione, testosterone, $5 \alpha$ - and/or $5 \beta$-dihydrotestosterone and estradiol-17 $\beta$ were produced from the precursor pregnenolone (Haraguchi et al., 2012b) (Figure 1). Isomers, such as $7 \alpha$ - and $7 \beta$ hydroxypregnenolone; allopregnanolone and epipregnanolone; and $5 \alpha$ - and $5 \beta$-dihydrotestosterone, were not separated by HPLC analysis, but GC-MS analysis was capable of separating several pairs of isomers (Haraguchi et al., 2012b). As summarized in Figure 1, pregnenolone, $7 \alpha$ - and $7 \beta$-hydroxypregnenolone, progesterone, allopregnanolone, epipregnanolone, androstenedione, testosterone, $5 \alpha$ - and $5 \beta$-dihydrotestosterone, and estradiol$17 \beta$ were identified as the neurosteroids produced in the pineal gland (Haraguchi et al., 2012b). In sum, molecular and biochemical techniques have demonstrated that the pineal gland produces a variety of neurosteroids from cholesterol via pregnenolone in juvenile birds. This is the first observation of de novo neurosteroidogenesis in the pineal gland in any vertebrate.

\section{MAJOR PINEAL NEUROSTEROIDS}

We further investigated major neurosteroids formed and released in the pineal gland. Incubation of the pineal glands from juvenile birds with ${ }^{3} \mathrm{H}$-pregnenolone led primarily to the formation of $7 \alpha$ and/or 7 $\beta$-hydroxypregnenolone and allopregnanolone and/or epipregnanolone as revealed by HPLC analysis (Haraguchi et al., $2012 b)$. The formation of $7 \alpha$ - and/or $7 \beta$-hydroxypregnenolone and the expression $\mathrm{P} 450_{7 \alpha}$ mRNA in the pineal gland of juveniles were higher than those of adults (Haraguchi et al., 2012b). The formation of allopregnanolone and/or epipregnanolone and the expression of $5 \alpha$-reductase mRNA in the pineal gland of juveniles were also higher than those of adults (Haraguchi et al., 2012b). Surprisingly, in juvenile birds, the formation of $7 \alpha$ - and/or $7 \beta$ hydroxypregnenolone and the expression of $\mathrm{P}^{4} 50_{7 \alpha}$ mRNA in the pineal gland were higher than those in brain regions, such as the diencephalon and cerebellum (Haraguchi et al., 2012b). The formation of allopregnanolone and/or epipregnanolone and the expression of $5 \alpha$-reductase mRNA in the pineal gland were also higher than those in the diencephalon and cerebellum in juvenile birds (Haraguchi et al., 2012b). Thus, the pineal gland of juvenile birds produces $7 \alpha$ - and/or $7 \beta$-hydroxypregnenolone and allopregnanolone and/or epipregnanolone far more abundantly than brain tissue.

Subsequently, to clarify the release of neurosteroids from the pineal gland, the pineal glands of juvenile birds were cultured in medium 199. The released neurosteroids were measured by GC-MS. Unlike 7 $\beta$-hydroxypregnenolone and epipregnanolone, significant amounts of $7 \alpha$-hydroxypregnenolone and allopregnanolone were released from the pineal gland into the culture medium (Haraguchi et al., 2012b). Thus, it appears that $7 \alpha$-hydroxypregnenolone and allopregnanolone are the major neurosteroids secreted from the pineal gland (Haraguchi et al., 2012b) (Figure 1).

\section{BIOLOGICAL ACTION OF PINEAL ALLOPREGNANOLONE ON PURKINJE CELL SURVIVAL DURING DEVELOPMENT}

The two major pineal neurosteroids, $7 \alpha$-hydroxypregnenolone and allopregnanolone, are abundantly released from the pineal gland during development (Haraguchi et al., 2012b). Therefore, these major pineal neurosteroids may play important roles in the avian brain during development. In birds, the pineal gland is located near the cerebellum (Figure 2). The Purkinje cell integrates the process of memory and learning. It has been reported that, in birds and mammals, pinealectomy $(\mathrm{Px})$ induces cell loss in the brain including Purkinje cells during development (Kilic et al., 2002; Tunç et al., 2006). Based on these findings, we hypothesized that allopregnanolone and/or $7 \alpha$-hydroxypregnenolone secreted by the pineal gland may play a role in preventing the death of developing Purkinje cells. To test this hypothesis, we conducted a series of experiments in the male juvenile birds. Px decreased the concentration of allopregnanolone in the cerebellum and induced apoptosis of Purkinje cells, whereas administration of allopregnanolone to Px birds increased allopregnanolone concentration in the cerebellum and prevented apoptosis of Purkinje cells (Haraguchi et al., 2012b). We further indicated that pineal allopregnanolone reaches Purkinje cells in the cerebellum by diffusion shown by injection of ${ }^{3} \mathrm{H}$-allopregnanolone close to the pineal lumen (Haraguchi et al., 2012b). Thus, allopregnanolone secreted by the pineal gland is considered to be a key factor for Purkinje cell survival during development (Figure 2).

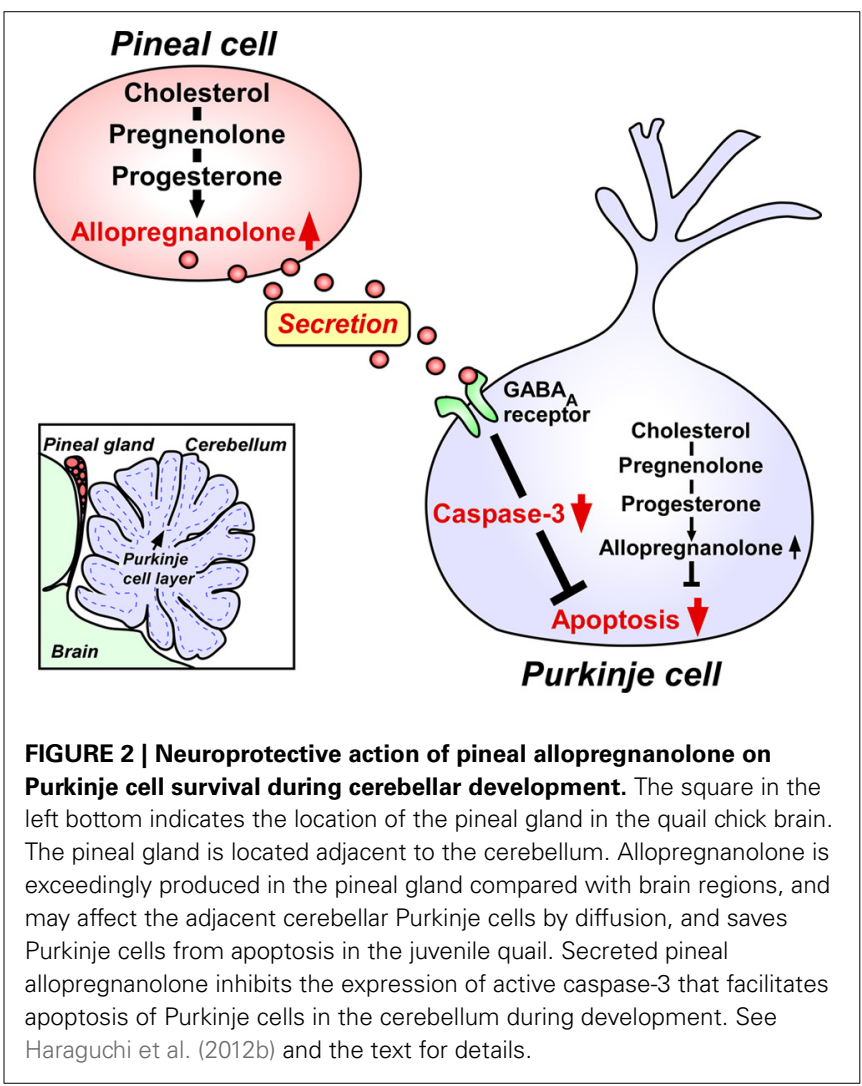


In contrast to allopregnanolone, administration of $7 \alpha$ hydroxypregnenolone to Px birds did not increase Purkinje cell survival (Haraguchi et al., 2012b). Although $7 \alpha-$ hydroxypregnenolone did not facilitate Purkinje cell survival, recent studies have demonstrated that this neurosteroid is involved in the regulation of locomotor rhythms of birds (Tsutsui et al., 2008; Hatori et al., 2011).

The induction of cell death of Purkinje cells in the cerebellum by Px suggests that certain other component(s) in the pineal gland may contribute to Purkinje cell survival during development. However, pineal melatonin did not facilitate Purkinje cell survival during development in juvenile birds (Haraguchi et al., 2012b). It thus appears that allopregnanolone but not melatonin acts as an important component of the pineal gland for Purkinje cell survival during development. Allopregnanolone produced in the pineal gland is considered to reach the target site within the cerebellum by diffusion, because allopregnanolone was abundantly released from cultured pineal gland of juvenile birds (Haraguchi et al., 2012b).

\section{MODE OF ACTION OF PINEAL ALLOPREGNANOLONE ON PURKINJE CELL SURVIVAL DURING DEVELOPMENT}

Finally, we investigated the mode of action of pineal allopregnanolone on Purkinje cell survival. Caspase-3, a crucial mediator of apoptosis, is known to play an important role in Purkinje cell death in vertebrates (Puig and Ferrer, 2001; Matsunaga et al., 2004b; Olkowski et al., 2008). Interestingly, Px increased the number of Purkinje cells that expressed active caspase- 3 in juvenile birds and administration of allopregnanolone to Px birds decreased the number of Purkinje cells expressing active caspase-3 (Haraguchi et al., 2012b). Accordingly, the neuroprotective effect of pineal allopregnanolone on Purkinje cells is accompanied with the decrease in caspase- 3 activity during development. We thus provide new evidence that pineal allopregnanolone exerts antiapoptotic effects in Purkinje cells by suppressing the activity of caspase-3 during development (Figure 2).

It is unclear whether the action of pineal allopregnanolone on caspase- 3 activity in the Purkinje cell is rapid (i.e., mediated through a membrane receptor) or slow (i.e., involving transcriptional activation). On the other hand, the action of allopregnanolone produced in the brain is likely mediated through interaction with the pathway of $\gamma$-aminobutyric acid type $A$ $\left(\mathrm{GABA}_{\mathrm{A}}\right)$ receptor, since allopregnanolone is a potent allosteric modulator of $\mathrm{GABA}_{\mathrm{A}}$ receptor (Paul and Purdy, 1992; Lambert et al., 1995). However, the mode of action of pineal allopregnanolone suppressing the activity of caspase- 3 in the Purkinje cell remains unclear. We need to clarify the mode of action exerting neuroprotective effect of pineal allopregnanolone in the Purkinje cell.

\section{INVOLVEMENT OF PINEAL AND BRAIN ALLOPREGNANOLONE IN PURKINJE CELL SURVIVAL DURING DEVELOPMENT}

The Purkinje cell is known as a major site of neurosteroid formation in the brain of various vertebrates (for reviews, see Tsutsui, 2008a,b). In mammals, the Purkinje cell possesses several kinds of steroidogenic enzymes, such as P450scc and $3 \beta-H S D$, and actively produces progesterone during neonatal life (Furukawa et al., 1998; Ukena et al., 1998, 1999) (Figure 2). Allopregnanolone is also synthesized in the neonatal cerebellum (Tsutsui and Ukena, 1999; Tsutsui et al., 2003b,c, 2004; Agís-Balboa et al., 2006, 2007) (Figure 2). Subsequently, biological actions of progesterone (Sakamoto et al., 2001b, 2002, 2003b; Ghoumari et al., 2003) and allopregnanolone (Griffin et al., 2004; Langmade et al., 2006) have been demonstrated by the studies on mammals using the Purkinje cell. In addition, this neuron expresses P450arom, a key enzyme of estrogen formation, and actively produces estradiol$17 \beta$ in the neonate (Sakamoto et al., 2003a; Tsutsui et al., 2003b). Estradiol-17 $\beta$ also contributes to important events in the developing Purkinje cell (Sakamoto et al., 2003a; Sasahara et al., 2007). Purkinje cells express the receptors for progesterone and estradiol-17 $\beta$ and these neurosteroids promote dendritic growth, spinogenesis, and synaptogenesis of Purkinje cells via each cognate nuclear receptor during cerebellar development (Sakamoto et al., 2001b, 2002, 2003a,b; Sasahara et al., 2007).

It has been shown that allopregnanolone produced in the cerebellum is involved in Purkinje and granule cell survival (Griffin et al., 2004; Langmade et al., 2006) (Figure 2), although allopregnanolone failed to promote dendritic growth, spinogenesis, and synaptogenesis of Purkinje cells (Sakamoto et al., 2001b, 2002). The Niemann-Pick type C (NP-C) mouse has been used as an excellent animal model for understanding the action of allopregnanolone. NP-C is an autosomal recessive, childhood neurodegenerative disease characterized by defective intracellular cholesterol trafficking, resulting in Purkinje cell degeneration as well as neuronal degeneration in other regions. Brains from adult NP-C mice contained less allopregnanolone than wild-type (WT) brain (Griffin et al., 2004). Administration of allopregnanolone to neonatal NP-C mice increased Purkinje cell survival and delayed neurodegeneration (Griffin et al., 2004). According to Langmade et al. (2006), Purkinje cell number was reduced in $n p c 1^{-/-}$mice, a model of NP-C disease, compared with WT mice. Thus, allopregnanolone produced in the cerebellum acts as a survival factor of Purkinje cells in the neonate (Griffin et al., 2004; Langmade et al., 2006) (Figure 2).

In addition to these findings, our recent studies on juvenile birds have demonstrated that the pineal gland is a major site of production of neurosteroids de novo from cholesterol (Hatori et al., 2011; Haraguchi et al., 2012b; Tsutsui et al., 2013a). Notably, allopregnanolone is exceedingly produced in the pineal gland compared with the brain and this major pineal neurosteroid is abundantly released from the pineal gland (Haraguchi et al., 2012b; Tsutsui et al., 2013b,c). Importantly, allopregnanolone secreted by the pineal gland prevents cell death of Purkinje cells by suppressing the activity of caspase-3, a crucial mediator of apoptosis, in the cerebellum during development (Haraguchi et al., 2012b; Tsutsui et al., 2013b,c). Taken together, it appears that both pineal allopregnanolone and cerebellar allopregnanolone are involved in Purkinje cell survival during development (Figure 2).

\section{CONCLUSIONS AND FUTURE DIRECTIONS}

The pineal gland actively produces neurosteroids de novo from cholesterol in juvenile birds. This is a new aspect of the biosynthesis of neurosteroids, because it was accepted that 
neurosteroids are produced only in glial cells and neurons which are located in the brain and peripheral nervous systems. The major pineal neurosteroid allopregnanolone prevents cell death of Purkinje cells by suppressing the activity of caspase- 3 during development. P450scc is expressed in the cells forming follicular structures in the pineal gland (Haraguchi et al., 2012b). Further study is needed to determine which cell types within the pineal gland, such as epithelial cells and/or neuronal cells express steroidogenic enzymes, P450scc, $3 \alpha$ - and $3 \beta$-HSD, $5 \alpha$-reductase, etc. The coordinated action of steroidogenic enzymes is essential for neurosteroidogenesis. As for the production of allopregnanolone in the pineal gland, the coordinated action of P450scc, $3 \alpha$ - and $3 \beta$-HSD and $5 \alpha$-reductase is required. Therefore, future study is also needed to determine whether all these enzymes are expressed in the same cell. Interaction of pineal and brain allopregnanolone in the regulation of brain development deserves further investigations. Px not only induces cell loss in the brain including Purkinje cells during development (Kilic et al., 2002; Tunç et al., 2006) but also abolishes circadian rhythm of locomotor activity (Gaston and Menaker, 1968; Tsutsui et al., 2008). In addition, allopregnanolone administration increases locomotion (Darbra and Pallarès, 2009). These observations indicate that pineal allopregnanolone may play an important role in the regulation of circadian locomotor activity.

\section{ACKNOWLEDGMENTS}

This work was supported by grants (22132004 and 22227002) to Kazuyoshi Tsutsui from the Ministry of Education, Science, and Culture of Japan. The authors thank Drs. H. Vaudry and Y. Fukada for their valuable discussions.

\section{REFERENCES}

Agís-Balboa, R. C., Pinna, G., Pibiri, F., Kadriu, B., Costa, E., and Guidotti, A. (2007). Down-regulation of neurosteroid biosynthesis in corticolimbic circuits mediates social isolation-induced behavior in mice. Proc. Natl. Acad. Sci. U.S.A. 104, 18736-18741. doi: 10.1073/pnas.0709419104

Agís-Balboa, R. C., Pinna, G., Zhubi, A., Maloku, E., Veldic, M., Costa, E., et al. (2006). Characterization of brain neurons that express enzymes mediating neurosteroid biosynthesis. Proc. Natl. Acad. Sci. U.S.A. 103, 14602-14607. doi: 10.1073/pnas.0606544103

Baulieu, E. E. (1997). Neurosteroids: of the nervous system, by the nervous system, for the nervous system (review). Recent Prog. Horm. Res. 52, 1-32.

Beaujean, D., Mensah-Nyagan, A. G., Do-Rego, J. L., Luu-The, V., Pelletier, G., and Vaudry, H. (1999). Immunocytochemical localization and biological activity of hydroxysteroid sulfotransferase in the frog brain. J. Neurochem. 72, 848-857. doi: 10.1046/j.1471-4159.1999.720848.x

Brion, F., Le Page, Y., Piccini, B., Cardoso, O., Tong, S. K., Chung, B. C., et al. (2012). Screening estrogenic activities of chemicals or mixtures in vivo using transgenic (cyp19a1b-GFP) zebrafish embryos. PLoS ONE 7:e36069. doi: 10.1371/journal.pone.0036069

Bruzzone, F., Do-Rego, J. L., Luu-The, V., Pelletier, G., Vallarino, M., and Vaudry, H. (2010). Immunohistochemical localization and biological activity of $3 \beta$ hydroxysteroid dehydrogenase and $5 \alpha$-reductase in the brain of the frog, Rana esculenta, during development. J. Chem. Neuroanat. 39, 35-50. doi: 10.1016/j.jchemneu.2009.08.001

Compagnone, N. A., Bulfone, A., Rubenstein, J. L., and Mellon, S. H. (1995). Steroidogenic enzyme P450c17 is expressed in the embryonic central nervous system. Endocrinology 136, 5212-5223. doi: 10.1210/endo.136.11.7588260

Compagnone, N. A., and Mellon, S. H. (2000). Neurosteroids: biosynthesis and function of these novel neuromodulators (review). Front. Neuroendocrinol. 21, 1-56. doi: 10.1006/frne.1999.0188

Corpéchot, C., Robel, P., Axelson, M., Sjövall, J., and Baulieu, E. E. (1981). Characterization and measurement of dehydroepiandrosterone sulfate in rat brain. Proc. Natl. Acad. Sci. U.S.A. 78, 4704-4707. doi: 10.1073/pnas.78. 8.4704

Corpéchot, C., Synguelakis, M., Talha, S., Axelson, M., Sjövall, J., Vihko, R., et al. (1983). Pregnenolone and its sulfate ester in rat brain. Brain Res. 270, 119-125. doi: 10.1016/0006-8993(83)90797-7

Darbra, S., and Pallarès, M. (2009). Neonatal allopregnanolone increases noveltydirected locomotion and disrupts behavioural responses to $\mathrm{GABA}_{A}$ receptor modulators in adulthood. Int. J. Dev. Neurosci. 27, 617-625. doi: 10.1016/j.ijdevneu.2009.05.008

Diotel, N., Do-Rego, J. L., Anglade, I., Vaillant, C., Pellegrini, E., Gueguen, M. M., et al. (2011). Activity and expression of steroidogenic enzymes in the brain of adult zebrafish. Eur. J. Neurosci. 34, 45-56. doi: 10.1111/j.14609568.2011.07731.x

Do-Rego, J. L., Seong, J. Y., Burel, D., Leprince, J., Luu-The, V., Tsutsui, K., et al. (2009). Neurosteroid biosynthesis: enzymatic pathways and neuroendocrine regulation by neurotransmitters and neuropeptides (review). Front. Neuroendocrinol. 30, 259-301. doi: 10.1016/j.yfrne.2009. 05.006

Do-Rego, J. L., Tremblay, Y., Luu-The, V., Repello, E., Vallarino, M., Belanger, A., et al. (2007). Immunocytochemical localization and biological activity of the steroidogenic enzyme cytochrome P450 17 $\alpha$-hydroxylase/C17, 20-lyase $\left(\mathrm{P} 450_{\mathrm{C} 17}\right)$ in the frog brain and pituitary. J. Neurochem. 100, 251-268. doi: 10.1111/j.1471-4159.2006.04209.x

Freking, F., Nazairians, T., and Schlinger, B. A. (2000). The expression of the sex steroid-synthesizing enzymes CYP11A1, 3 -HSD, CYP17, and CYP 19 in gonads and adrenals of adult and developing zebra finches. Gen. Comp. Endocrinol. 119, 140-151. doi: 10.1006/gcen.2000.7503

Furukawa, A., Miyatake, A., Ohnishi, T., and Ichikawa, Y. (1998). Steroidogenic acute regulatory protein (StAR) transcripts constitutively expressed in the adult rat central nervous system: colocalization of StAR, cytochrome P-450scc (CYP XIA1), and $3 \beta$-hydroxysteroid dehydrogenase in the rat brain. J. Neurochem. 71, 2231-2238. doi: 10.1046/j.1471-4159.1998.71062231.x

Gaston, S., and Menaker, M. (1968). Pineal function: the biological clock in the sparrow? Science 160, 1125-1127. doi: 10.1126/science.160.3832.1125

Ghoumari, A. M., Dusart, I., El-Etr, M., Tronche, F., Sotelo, C., Schumacher, M., et al. (2003). Mifepristone (RU486) protects Purkinje cells from cell death in organotypic slice cultures of postnatal rat and mouse cerebellum. Proc. Natl. Acad. Sci. U.S.A. 100, 7953-7958. doi: 10.1073/pnas.1332667100

Griffin, L. D., Gong, W., Verot, L., and Mellon, S. H. (2004). Niemann-Pick type $\mathrm{C}$ disease involves disrupted neurosteroidogenesis and responds to allopregnanolone. Nat. Med. 10, 704-711. doi: 10.1038/nm1073

Guarneri, P., Guarneri, R., Cascio, C., Pavasant, P., Piccoli, F., and Papadopoulos, V. (1994). Neurosteroidogenesis in rat retinas. J. Neurochem. 63, 86-96. doi: 10.1046/j.1471-4159.1994.63010086.x

Haraguchi, S., Hara, S., Ubuka, T., Mita, M., and Tsutsui, K. (2012b). Possible role of pineal allopregnanolone in Purkinje cell survival. Proc. Natl. Acad. Sci. U.S.A. 109, 21110-21115. doi: 10.1073/pnas.1210804109

Haraguchi, S., Koyama, T., Hasunuma, I., Okuyama, S., Ubuka, T., Kikuyama, S., et al. (2012a). Acute stress increases the synthesis of $7 \alpha$-hydroxypregnenolone, a new key neurosteroid stimulating locomotor activity, through corticosterone action in newts. Endocrinology 153, 794-805. doi: 10.1210/en. 2011-1422

Haraguchi, S., Koyama, T., Hasunuma, I., Vaudry, H., and Tsutsui, K. (2010). Prolactin increases the synthesis of $7 \alpha$-hydroxypregnenolone, a key factor for induction of locomotor activity, in breeding male newts. Endocrinology 151, 2211-2222. doi: 10.1210/en.2009-1229

Hatori, M., Hirota, T., Iitsuka, M., Kurabayashi, N., Haraguchi, S., Kokame, K., et al. (2011). Light-dependent and circadian clock-regulated activation of sterol regulatory element-binding protein, X-box-binding protein 1, and heat shock factor pathways. Proc. Natl. Acad. Sci. U.S.A. 108, 4864-4869. doi: 10.1073/pnas. 1015959108

Hojo, Y., Hattori, T. A., Enami, T., Furukawa, A., Suzuki, K., Ishii, H. T., et al. (2004). Adult male rat hippocampus synthesizes estradiol from pregnenolone by cytochromes $\mathrm{P} 45017 \alpha$ and $\mathrm{P} 450$ aromatase localized in neurons. Proc. Natl. Acad. Sci. U.S.A. 101, 865-870. doi: 10.1073/pnas. 2630225100

Inai, Y., Nagai, K., Ukena, K., Oishi, T., and Tsutsui, K. (2003). Seasonal changes in neurosteroid concentrations in the amphibian brain and environmental factors regulating their changes. Brain Res. 959, 214-225. doi: 10.1016/S00068993(02)03745-9 
Jo, D. H., Abdallah, M. A., Young, J., Baulieu, E. E., and Robel, P. (1989). Pregnenolone, dehydroepiandrosterone, and their sulfate and fatty acid esters in the rat brain. Steroids 54, 287-297. doi: 10.1016/0039-128X(89)90003-2

Kilic, E., Hermann, D. M., Isenmann, S., and Bähr, M. (2002). Effects of pinealectomy and melatonin on the retrograde degeneration of retinal ganglion cells in a novel model of intraorbital optic nerve transection in mice. J. Pineal Res. 32, 106-111. doi: 10.1034/j.1600-079x.2002.1823.x

Kimoto, T., Tsurugizawa, T., Ohta, Y., Makino, J., Tamura, H., Hojo, Y., et al. (2001). Neurosteroid synthesis by cytochrome p450-containing systems localized in the rat brain hippocampal neurons: $N$-methyl-D-aspartate and calcium-dependent synthesis. Endocrinology 142, 3578-3589. doi: 10.1210/endo.142.8.8327

Lambert, J. J., Belelli, D., Hill-Venning, C., and Peters, J. A. (1995). Neurosteroids and $\mathrm{GABA}_{A}$ receptor function. Trends Pharmacol. Sci. 16, 295-303. doi: 10.1016/S0165-6147(00)89058-6

Langmade, S. J., Gale, S. E., Frolov, A., Mohri, I., Suzuki, K., Mellon, S. H., et al. (2006). Pregnane X receptor (PXR) activation: a mechanism for neuroprotection in a mouse model of Niemann-Pick C disease. Proc. Natl. Acad. Sci. U.S.A. 103, 13807-13812. doi: 10.1073/pnas.0606218103

Lanthier, A., and Patwardhan, V. V. (1986). Sex steroids and 5-en-3 $\beta$ hydroxysteroids in specific regions of the human brain and cranial nerves. $J$. Steroid Biochem. 25, 445-449. doi: 10.1016/0022-4731(86)90259-1

London, S., Monks, D. A., Wade, J., and Schlinger, B. A. (2006). Widespread capacity for steroid synthesis in the avian brain and song system. Endocrinology 147, 5975-5987. doi: 10.1210/en.2006-0154

London, S., and Schlinger, B. A. (2007). Steroidogenic enzymes along the ventricular proliferative zone in the developing songbird brain. J. Comp. Neurol. 502, 507-521. doi: 10.1002/cne.21335

London, S. E., Boulter, J., and Schlinger, B. A. (2003). Cloning of the zebra finch androgen synthetic enzyme CYP17: a study of its neural expression throughout posthatch development. J. Comp. Neurol. 467, 496-508. doi: 10.1002/cne.10936

London, S. E., Itoh, Y., Lance, V. A., Wise, P. M., Ekanayake, P. S., Oyama, R. K. et al. (2010). Neural expression and post-transcriptional dosage compensation of the steroid metabolic enzyme 17 $\beta$-HSD type 4. BMC Neurosci. 11:47. doi: 10.1186/1471-2202-11-47

Mathur, C., Prasad, V. V., Raju, V. S., Welch, M., and Lieberman, S. (1993). Steroids and their conjugates in the mammalian brain. Proc. Natl. Acad. Sci. U.S.A. 90, 85-88. doi: 10.1073/pnas.90.1.85

Matsunaga, E., Tauszig-Delamasure, S., Monnier, P. P., Mueller, B. K., Strittmatter, S. M., Mehlen, P., et al. (2004b). RGM and its receptor neogenin regulate neuronal survival. Nat. Cell Biol. 6, 749-755. doi: 10.1038/ncb1157

Matsunaga, M., Ukena, K., Baulieu, E. E., and Tsutsui, K. (2004a). $7 \alpha-$ Hydroxypregnenolone acts as a neuronal activator to stimulate locomotor activity of breeding newts by means of the dopaminergic system. Proc. Natl. Acad. Sci. U.S.A. 101, 17282-17287. doi: 10.1073/pnas.0407176101

Matsunaga, M., Ukena, K., and Tsutsui, K. (2001). Expression and localization of cytochrome P450 17 $\alpha$-hydroxylase/c17, 20-lyase in the avian brain. Brain Res. 899, 112-122. doi: 10.1016/S0006-8993(01)02217-X

Matsunaga, M., Ukena, K., and Tsutsui, K. (2002). Androgen biosynthesis in the quail brain. Brain Res. 948, 180-185. doi: 10.1016/S0006-8993(02)03147-5

Mellon, S. H., and Deschepper, C. F. (1993). Neurosteroid biosynthesis: genes for adrenal steroidogenic enzymes are expressed in the brain. Brain Res. 629, 283-292. doi: 10.1016/0006-8993(93)91332-M

Mellon, S. H., and Vaudry, H. (2001). Biosynthesis of neurosteroids and regulation of their synthesis (review). Int. Rev. Neurobiol. 46, 33-78. doi: 10.1016/S00747742(01)46058-2

Mensah-Nyagan, A. G., Do-Rego, J. L., Beaujean, D., Luu-The, V., Pelletier, G., and Vaudry, H. (1999). Neurosteroids: expression of steroidogenic enzymes and regulation of steroid biosynthesis in the central nervous system (review). Pharmacol. Rev. 51, 63-81.

Mensah-Nyagan, A. G., Do-Rego, J. L., Feuilloley, M., Marcual, A., Lange, C., Pelletier, G., et al. (1996a). In vivo and in vitro evidence for the biosynthesis of testosterone in the telencephalon of the female frog. J. Neurochem. 67, 413-422. doi: 10.1046/j.1471-4159.1996.67010413.x

Mensah-Nyagan, A. G., Feuilloley, M., Do-Rego, J. L., Marcual, A., Lange, C., Tonon, M. C., et al. (1996b). Localization of 17 $\beta$-hydroxysteroid dehydrogenase and characterization of testosterone in the brain of the male frog. Proc. Natl. Acad. Sci. U.S.A. 93, 1423-1428. doi: 10.1073/pnas.93.4.1423

Mensah-Nyagan, A. G., Feuilloley, M., Dupont, E., Do-Rego, J. L., Leboulenger, F., Pelletier, G., et al. (1994). Immunocytochemical localization and biological activity of $3 \beta$-hydroxysteroid dehydrogenase in the central nervous system of the frog. J. Neurosci. 14, 7306-7318.

Menuet, A., Pellegrini, E., Brion, F., Gueguen, M. M., Anglade, I., Pakdel, F., et al. (2005). Expression and estrogen-dependent regulation of the zebrafish brain aromatase gene. J. Comp. Neurol. 485, 304-320. doi: 10.1002/cne.20497

Okamoto, M., Hojo, Y., Inoue, K., Matsui, T., Kawato, S., McEwen, B., et al. (2012). Mild exercise increases dihydrotestosterone in hippocampus providing evidence for androgenic mediation of neurogenesis. Proc. Natl. Acad. Sci. U.S.A. 109, 13100-13105. doi: 10.1073/pnas.1210023109

Olkowski, A. A., Wojnarowicz, C., Nain, S., Ling, B., Alcorn, J. M., and Laarveld, B. (2008). A study on pathogenesis of sudden death syndrome in broiler chickens. Res. Vet. Sci. 85, 131-140. doi: 10.1016/j.rvsc.2007.08.006

Paul, S. M., and Purdy, R. H. (1992). Neuroactive steroids. FASEB J. 6, 2311-2322. Puig, B., and Ferrer, I. (2001). Cell death signaling in the cerebellum in CreutzfeldtJakob disease. Acta Neuropathol. 102, 207-215. doi: 10.1007/s004010100368

Robel, P., and Baulieu, E. E. (1985). Neuro-steroids, $3 \beta$-hydroxy- $\Delta^{5}$-derivatives in the rodent brain. Neurochem. Int. 7, 953-958. doi: 10.1016/01970186(85)90143-3

Robel, P., Bourreau, E., Corpéchot, C., Dang, D. C., Halberg, F., Clarke, C., et al. (1987). Neuro-steroids: $3 \beta$-hydroxy- $\Delta 5$-derivatives in rat and monkey brain. $J$. Steroid Biochem. 27, 649-655. doi: 10.1016/0022-4731(87)90133-6

Sakamoto, H., Mezaki, Y., Shikimi, H., Ukena, K., and Tsutsui, K. (2003a). Dendritic growth and spine formation in response to estrogen in the developing Purkinje cell. Endocrinology 144, 4466-4477. doi: 10.1210/en. 2003-0307

Sakamoto, H., Shikimi, H., Ukena, K., and Tsutsui, K. (2003b). Neonatal expression of progesterone receptor isoforms in the cerebellar Purkinje cell in rats. Neurosci. Lett. 343, 163-166. doi: 10.1016/S0304-3940(03)00362-8

Sakamoto, H., Ukena, K., and Tsutsui, K. (2001a). Activity and localization of $3 \beta$-hydroxysteroid dehydrogenase $/ \Delta^{5}-\Delta^{4}$-isomerase in the zebrafish central nervous system. J. Comp. Neurol. 439, 291-305. doi: 10.1002/cne.1351

Sakamoto, H., Ukena, K., and Tsutsui, K. (2001b). Effects of progesterone synthesized de novo in the developing Purkinje cell on its dendritic growth and synaptogenesis. J. Neurosci. 21, 6221-6232.

Sakamoto, H., Ukena, K., and Tsutsui, K. (2002). Dendritic spine formation in response to progesterone synthesized de novo in the developing Purkinje cell in rats. Neurosci. Lett. 322, 111-115. doi: 10.1016/S0304-3940(02) 00077-0

Sasahara, K., Shikimi, H., Haraguchi, S., Sakamoto, H., Honda, S., Harada, N., et al (2007). Mode of action and functional significance of estrogen-inducing dendritic growth, spinogenesis, and synaptogenesis in the developing Purkinje cell. J. Neurosci. 277, 408-7417. doi: 10.1523/JNEUROSCI.0710-07.2007

Schlinger, B. A., Lane, N. I., Grisham, W., and Thompson, L. (1999). Androgen synthesis in a songbird: a study of cyp17 (17 $\alpha$-hydroxylase/c17,20lyase) activity in the zebra finch. Gen. Comp. Endocrinol. 113, 46-58. doi: 10.1006/gcen.1998.7179

Soma, K. K., Alday, N. A., Hau, M., and Schlinger, B. A. (2004). Dehydroepiandrosterone metabolism by $3 \beta$-hydroxysteroid dehydrogenase/ $\Delta^{5}$ $\Delta^{4}$-isomerase in adult zebra finch brain: sex difference and rapid effect of stress. Endocrinology 145, 1668-1677. doi: 10.1210/en.2003-0883

Takase, M., Haraguchi, S., Hasunuma, I., Kikuyama, S., and Tsutsui, K. (2011). Expression of cytochrome P450 side-chain cleavage enzyme mRNA in the brain of the red-bellied newt Cynops pyrrhogaster. Gen. Comp. Endocrinol. 170, 468-474. doi: 10.1016/j.ygcen.2010.10.019

Takase, M., Ukena, K., and Tsutsui, K. (2002). Expression and localization of cytochrome P45011 $\beta$, aldo mRNA in the frog brain. Brain Res. 950, 288-296. doi: 10.1016/S0006-8993(02)03054-8

Takase, M., Ukena, K., Yamazaki, T., Kominami, S., and Tsutsui, K. (1999). Pregnenolone, pregnenolone sulfate and cytochrome P450 side-chain cleavage enzyme in the amphibian brain and their seasonal changes. Endocrinology 140, 1936-1944. doi: 10.1210/endo.140.4.6641

Tam, H., and Schlinger, B. A. (2007). Activities of $3 \beta-H S D$ and aromatase in slices of developing and adult zebra finch brain. Gen. Comp. Endocrinol. 150, 26-33. doi: 10.1016/j.ygcen.2006.07.001

Tsutsui, K. (2008a). Progesterone biosynthesis and action in the developing neuron (review). Endocrinology 149, 2757-2761. doi: 10.1210/en.2007-1592

Tsutsui, K. (2008b). Neurosteroids in the Purkinje cell: biosynthesis, mode of action and functional significance (review). Mol. Neurobiol. 37, 116-125. doi: 10.1016/j.jsbmb.2006.09.015 
Tsutsui, K., Haraguchi, S., Fukada, Y., and Vaudry, H. (2013a). Brain and pineal $7 \alpha$-hydroxypregnenolone stimulating locomotor activity: identification, mode of action and regulation of biosynthesis (review). Front. Neuroendocrinol. 34, 179-189. doi: 10.1016/j.yfrne.2013.05.002

Tsutsui, K., Haraguchi, S., Hatori, M., Hirota, T., and Fukada, Y. (2013b). Biosynthesis and biological actions of pineal neurosteroids in domestic birds (review). Neuroendocrinology 98, 97-105. doi: 10.1159/000353782

Tsutsui, K., Haraguchi, S., Inoue, K., Miyabara, H., Ubuka, T., Hatori, M. et al. (2013c). New biosynthesis and biological actions of avian neurosteroids (review). J. Exp. Neurosci. 7, 15-29. doi: 10.4137/JEN.S11148

Tsutsui, K., Inoue, K., Miyabara, H., Suzuki, S., Ogura, Y., and Haraguchi, S. (2008). $7 \alpha$-Hydroxypregnenolone mediates melatonin action underlying diurnal locomotor rhythms. J. Neurosci. 28, 2158-2167. doi: 10.1523/JNEUROSCI.356207.2008

Tsutsui, K., Matsunaga, M., Miyabara, H., and Ukena, K. (2006). Neurosteroid biosynthesis in the quail brain (review). J. Exp. Zool. 305A, 733-742. doi: 10.1002/jez.a.302

Tsutsui, K., Matsunaga, M., and Ukena, K. (2003a). Biosynthesis and biological actions of neurosteroids in the avian brain (review). Avian Poultry Biol. Rev. 14, 63-78. doi: 10.3184/147020603783641297

Tsutsui, K., and Mellon, S. H. (2006). Neurosteroids in the brain neuron: biosynthesis, action and medicinal impact on neurodegenerative disease (review). Central Nerv. Syst. Agents Med. Chem. 6, 73-82. doi: 10.2174/187152406776056555

Tsutsui, K., Sakamoto, H., Shikimi, H., and Ukena, K. (2004). Organizing actions of neurosteroids in the Purkinje neuron (review). Neurosci. Res. 49, 273-279. doi: 10.1016/j.neures.2004.03.006

Tsutsui, K., Sakamoto, H., and Ukena, K. (2003b). Biosynthesis and action of neurosteroids in the cerebellar Purkinje neuron. J. Steroid Biochem. Mol Biol. 85, 311-321. doi: 10.1016/S0960-0760(03)00229-2

Tsutsui, K., and Schlinger, B. A. (2001). "Steroidogenesis in the avian brain," in Avian Endocrinology, eds A. Dawson and C. M. Chaturvedi (New Delhi, Narosa Publishing House), 59-77.

Tsutsui, K., and Ukena, K. (1999). Neurosteroids in the cerebellar Purkinje neuron and their actions (review). Int J. Mol. Med. 4, 49-56.

Tsutsui, K., Ukena, K., and Sakamoto, H. (2003c). A novel aspect of the cerebellum: biosynthesis of neurosteroids in the Purkinje cell (review). Cerebellum 2, 215-222. doi: 10.1080/14734220310016169

Tsutsui, K., Ukena, K., Takase, M., Kohchi, C., and Lea, R. W. (1999). Neurosteroid biosynthesis in vertebrate brains (review). Comp. Biochem. Physiol. C 124, 121-129.

Tsutsui, K., Ukena, K., Usui, M., Sakamoto, H., and Takase, M. (2000). Novel brain function: biosynthesis and actions of neurosteroids in neurons (review). Neurosci. Res. 36, 261-273. doi: 10.1016/S0168-0102(99)00132-7
Tsutsui, K., and Yamazaki, T. (1995). Avian neurosteroids. I. Pregnenolone biosynthesis in the quail brain. Brain Res. 678, 1-9. doi: 10.1016/0006-8993(95) 00116-8

Tsutsui, K., Yamazaki, T., Usui, M., Furukawa, Y., Ukena, K., Kohchi, C., et al. (1997). "P450scc activity in the brain," in Perspectives in Avian Endocrinology, eds S. Harvey and R. J. Etches (Bristol: Journal of Endocrinol Ltd.), 427-436.

Tunç, A. T., Turgut, M., Aslan, H., Sahin, B., Yurtseven, M. E., and Kaplan, S. (2006). Neonatal pinealectomy induces Purkinje cell loss in the cerebellum of the chick: a stereological study. Brain Res. 1067, 95-102. doi: 10.1016/j.brainres.2005.10.011

Ukena, K., Honda, Y., Lea, R. W., and Tsutsui, K. (2001). Developmental changes in progesterone biosynthesis and metabolism in the quail brain. Brain Res. 898 , 190-194. doi: 10.1016/S0006-8993(01)02162-X

Ukena, K., Kohchi, C., and Tsutsui, K. (1999). Expression and activity of $3 \beta$ hydroxysteroid dehydrogenase $/ \Delta^{5}-\Delta^{4}$-isomerase in the rat Purkinje neuron during neonatal life. Endocrinology 140, 805-813.

Ukena, K., Usui, M., Kohchi, C., and Tsutsui, K. (1998). Cytochrome P450 sidechain cleavage enzyme in the cerebellar Purkinje neuron and its neonatal change in rats. Endocrinology 139, 137-147.

Usui, M., Yamazaki, T., Kominami, S., and Tsutsui, K. (1995). Avian neurosteroids. II. Localization of a cytochrome P450scc-like substance in the quail brain. Brain Res. 678, 10-20. doi: 10.1016/0006-8993(95)00117-9

Vanson, A., Arnold, A. P., and Schlinger, B. A. (1996). 33-Hydroxysteroid dehydrogenase/isomerase and aromatase activity in primary cultures of developing zebra finch telencephalon: dehydroepiandrosterone as substrate for synthesis of androstenedione and estrogens. Gen. Comp. Endocrinol. 102, 342-350. doi: 10.1006/gcen.1996.0077

Conflict of Interest Statement: The authors declare that the research was conducted in the absence of any commercial or financial relationships that could be construed as a potential conflict of interest.

Received: 25 January 2014; paper pending published: 23 March 2014; accepted: 14 April 2014; published online: 05 May 2014.

Citation: Tsutsui K and Haraguchi S (2014) Biosynthesis and biological action of pineal allopregnanolone. Front. Cell. Neurosci. 8:118. doi: 10.3389/fncel.2014.00118 This article was submitted to the journal Frontiers in Cellular Neuroscience. Copyright (c) 2014 Tsutsui and Haraguchi. This is an open-access article distributed under the terms of the Creative Commons Attribution License (CC BY). The use, distribution or reproduction in other forums is permitted, provided the original author(s) or licensor are credited and that the original publication in this journal is cited, in accordance with accepted academic practice. No use, distribution or reproduction is permitted which does not comply with these terms. 